\title{
UNA ALTERNATIVA PARA INCENTIVAR Y CREAR LUGARES DE ACOGIDA
}

Yober P. Alcarazo V.*

\begin{abstract}
RESUMEN
Este es un artículo que nos permite reflexionar sobre la importancia que nos brindan los lugares y espacios de acogida en las familias de bajos recursos económicos. Creo, por mi experiencia de interno en La Casa de la Familia, al darles la posibilidad de "alimentarse" de forma distinta, mediante la palabra, el juego, con una escucha atenta, respetuosa, nuestra acogida y el vínculo, las familias puedan superar sus propias dificultades psicológicas.
\end{abstract}

Palabras claves: Lugares de acogida, palabra, juego, escucha, vínculo.

\begin{abstract}
This is an article that allows us to meditate about the importance that you/they offer us the places and welcome spaces in the families of low economic resources. I believe, for my experience of internal in The House of the Family, when giving them the possibility of "to feed" in a different way, by means of the word, the game, with one listens attentive, respectful and our welcome, the families can overcome their own psychological difficulties.
\end{abstract}

Keywords: Places of welcoming, word, game, listens, to link.

\section{BRINDANDO LA POSIBILIDAD DE "ALIMENTARSE" DE MANERA DISTINTA, MEDIANTE LA ACOGIDA, EL JUEGO, LA ESCUCHA Y LA PALABRA}

Permítanme compartir esta reflexión personal con todos ustedes. Sabemos que el tiempo y el proceso son los mejores aliados para comprender y entender mejor las cosas, es en ese camino que hoy puedo decir que tanto ha significado y significa para mí, la Casa de la Familia; y creo lo más importante, que tanto más significa para nuestra sociedad hoy.

La Casa de la Familia se encuentra ubicada en uno de los distritos más populares de Lima, en una calle donde abunda el consumo de drogas, consumo que muchos lo realizan a vista de sus propios vecinos. La calle es de una sola cuadra, es decir, tiene 100 metros de largo. Está ubicada muy cerca a "La Alameda de los Descalzos", un lugar histórico de la Lima Antigua. En aquella cuadra predominan la violencia, la delincuencia, el pandillaje, los robos; creemos por tanto, que las

* Egresado de la Facultad de Psicología de la UNMSM. Ex interno de la Casa de la Familia Email: 1810397@unmsm.edu.pe / yobera@latinmail.com 
carencias materiales y psicológicas por las que atraviesan estas familias deben ser grandes y particulares a la vez.

La Casa de la Familia es una entidad civil sin fines de lucro, constituida como un centro de promoción temprana en salud mental, la cual viene trabajando en el Perú desde el año 1989. En sus inicios se encontraba en el Centro de Lima, pero desde hace 6 años se trasladó al Jr. Portugués 193, distrito del Rímac. Esta institución, dirigida por su fundadora, la psicoanalista Dra. Bibiana Maza, que junto con un grupo de psicoterapeutas, han adaptado la exitosa propuesta del Instituto de Investigación Aplicada para la Pareja y el Niño (IRAEC) de Francia; tiene como objetivo a través de la técnica psicoanalítica: el lograr establecer una relación de vínculo más satisfactoria entre padres, hijos y el medio social.

Quiero hacer mención que en el año 2001 se obtuvo un reconocimiento del Banco Mundial por este innovador proyecto, por acceder a los sectores menos favorecidos de nuestra sociedad sin proporcionales algo "material-concreto", no se les brinda un pan, una sopa, un plato de comida, un vestido, un techo, ni dinero.

Es con los aportes desde el psicoanálisis, brindarles un lugar de acogida, escucha, palabra y juego. Espacios de atención donde las familias que asistan, puedan lograr establecer relaciones más armoniosas y satisfactorias. A partir de nuestra presencia, se busca acogerlos y encontrar conjuntamente algún sentido a las dificultades por las que atraviesan, poniendo una especial atención en rescatar aquellas habilidades que les son difíciles de disponer. El sentirse valorados y escuchados posibilita el cambio y una mejor libertad de elección; para que así logren fortalecerse, lo que contribuirá a un mejor desarrollo personal y emocional. A las familias, se les sostiene de esa manera, acompañándolas con una escucha atenta, respetuosa, nunca se les critica, eventualmente se le pregunta a los padres cómo fueron de niños, para que puedan lograr entender mejor a sus hijos. En la Casa se sienten libres, y eso es una muestra de lo valioso que les resulta compartir su intimidad familiar y por qué no, también su fragilidad. Creo que es una respuesta a lo que significa para ellos... "venir a jugar". Al juego de los niños hay que considerarlo como uno de sus actos más serios, pues se valen de ellos para resolver y dominar sus dificultades psicológicas, tanto del pasado, como del presente; el juego es un camino que nos transporta a su espacio interno, nos da la posibilidad de comprender también como ven e interpretan el mundo que los rodea, qué problemas le incomodan. Esto lo expresará de la manera que quiera, tal vez le resulte difícil hacerlo en palabras, pero si queremos entender su mundo interno, debemos aprender a andar en ese sentido.

La Casa abre sus puertas de lunes a viernes, desde las 3.30pm hasta las 6.30pm, lunes dedicados a los adolescentes, de martes a viernes asisten los niños hasta ocho años de edad, acompañados de sus padres. Todos ellos pasan una tarde de juego, todos son acogidos y aceptados tal como son, en esa medida se trabaja. El promedio de asistencia es de unas quince familias al día, si calculamos que cada familia vienen con dos niños, estamos hablando de seiscientas personas atendidas al mes.

Durante el año 2005, fuimos cuatro internos (tres de otras universidades), que conjuntamente con los demás profesionales realizamos nuestra labor clínica en nuestro local del distrito del Rímac y en convenio con la Maternidad de Lima, en el pabellón de madres adolescentes. La Casa de la Familia brinda al interno una formación integral; se cuenta con tutores que constantemente apoyan y se aprende sobre teoría y clínica psicoanalítica, en seminarios, lecturas, encuentros, congresos y supervisiones.

También publicamos una vez al año La revista azul, donde hay diversos artículos sobre la niñez, adolescencia, familia, vínculo, juego, etc. Esta labor se supervisa constantemente con el objetivo de ir conociendo el trabajo de acogida en las familias, así como lograr una mejor compresión de lo que significa la interrelación humana y la psicología de las familias.

La manera como me consolidó, tanto en mi proyección profesional y personal, hace que "La Casa de la Familia" haya sido la institución más adecuada para mi formación: Mi interés hacia el Psicoanálisis. Aunque nosotros creemos ser seres autónomos y de tener conciencia de nuestras 
motivaciones, el psicoanálisis pone de manifiesto que nuestra vida esta determinada por lo inconsciente que todos llevamos dentro.

Permítanme presentarles, a manera de ejemplo, la forma de abordaje e intervención que realizamos. Primeramente, tenemos algo que es muy claro para nosotros: El niño es una persona, y como tal, nos dirigimos hacia él o ella, y el juego nos va a comunicar algo del mundo interno del niño.

Este es el caso de una niña de tan solo 3 años, cuyo nombre es Alexandra*. Ella se encontraba una tarde "jugando" en un espacio de la casa, exactamente en la cocina. Observé que estaba sola y sentada, habían unos platos, tazas y otros juguetes sobre la mesa; a ella se la veía como "paralizadacontemplando" aquellos juguetes. Acercándome hacia ella, la saludé y le dije: "Hola Alexandra, ¿cómo estás?", ella solo me miró sin decirme absolutamente nada, y yo sentí en su mirada algo así como sorprenderse interiormente por alguien que en ese momento la estaba "acompañando". Respetando su tiempo y su mirada, volví a decirle: ¿Y hoy qué te vas a preparar Alexandra, qué vas a cocinar? Hubo solo silencio, no hubo respuesta alguna, ella miraba, observaba. Yo hasta ese momento pensaba que tal vez mi presencia sea un obstáculo para que ella pudiera desarrollar su juego, pensé que solo quería estar sola, no hablaba para nada, y en ese espacio de "su juego". Ya estaba por retirarme y le dije: "Alexandra, puedes tomar los juguetes que quieras, yo estaré por acá por si necesitas cualquier cosa".

Cuando estaba a punto de pararme, ella inmediatamente me dio unos platitos, yo se los recibí y le dije: ¡Uhhh, qué rica esta tú comida!, y así durante un largo rato solo me servía para dar, no permitía que yo le pueda devolver lo mismo, cuando lo hacía, inmediatamente me lo quitaba con una sonrisa. Sentí que ella se estaba permitiendo "disfrutar y jugar". Ya había entrado y entendía su juego, o lo que tal vez ella solo quería comunicar: Su soledad, sus carencias afectivas, su depresión, ..., son solo mis hipótesis. Cuando ya estábamos por cerrar la Casa, y a manera de despedirme, le dije: "Alexandra, si quieres conversar o contarnos cómo te estás sintiendo, puedes hacerlo cuando tú quieras, cuando lo desees".

Solo noté en ella un rostro de mayor tranquilidad, el solo mirar ahora ya con una ligera sonrisa, era una mirada que me hacía reflexionar; pensaba en lo que ella quería y quiere comunicar, qué significaría para ella ese su silencio, el querer ser ella quien solo sirva, ¿o tal vez sea la necesidad de la presencia de alguien para que se sienta más segura y permitirse ser más libre? Ya poco a poco irá comunicándonos lo que ella quiera, cuando quiera tal vez nos hable de la ausencia de un padre y/o una madre, de sus pérdidas, de sus fantasías, o comunicándonos tan sólo su deseo y también sus anhelos.

Pasado un tiempo, nos enteramos que su madre era prostituta y su padre aparentemente un delincuente, con ambos ella no vivía, era la familia de la madre quien se estaba haciendo cargo de ella y se la llevaron a otro lugar del Perú para que, según dicen ellos, esté mucho mejor y tenga una vida más saludable, sin la presencia y "modelo" de sus padres.

Pienso que el juego es el "camino real" que nos lleva al mundo interno consciente e inconsciente del niño. El juego nos permite comprender cómo un niño ve e interpreta el mundo, lo que le gustaría que fuese, cuáles son sus inquietudes, qué problemas lo acosan, "ningún niño juega por gusto". El juego que elige se ve motivado por procesos internos, deseos, problemas, ansiedades, etc. Lo que sucede en su mente determina sus actividades lúdicas, "el juego es su lenguaje secreto aunque no lo entendamos". El niño suele hacerlo de manera simbólica que con frecuencia, hasta a él mismo le costará entenderlo, ya que su origen está escondido profundamente en su inconsciente.

Tal vez también para nosotros tenga poco sentido comprender su juego en ese momento; pero lo mejor que debemos hacer es solo aprobar su juego sin entrometernos. Nosotros acompañamos el juego de los niños, seguimos su ritmo, ellos nos expresan sus fantasías o lo que sienten y nosotros les expresamos palabras que recogen lo que el niño está viviendo. En cuanto a los adultos, no damos consejos, ya que si bien estos pueden ser muy adecuados, no funcionan mientras no haya una compresión de la dificultad que implique el afecto y la razón. 
Cuando Freud descubrió la dinámica de lo inconsciente, realizó el mayor de sus aportes a la compresión de la mente humana, el Psicoanálisis, el cual nos permite, de manera profunda, analizar nuestra vida inconsciente y comprender mejor nuestros actos y pensamientos, lo cual nos dará la posibilidad de llevar una vida mas saludable, durante el proceso terapéutico y/o al final de ello.

Por todo ello, mi elección por haber realizado mis prácticas preprofesionales -internado, en la Casa de la Familia, se debe a que confío en el Psicoanálisis, creo que es una posibilidad de cambio terapéutico. Es necesario para lograr entender de manera profunda el trabajo "analítico", pasar por un proceso terapéutico psicoanalítico personal; cada uno de mis compañeros internistas lo han estado y lo siguen estando, al igual que yo. Por eso, el tratamiento psicoanalítico es una labor conjunta entre analista y paciente, que tiene por objetivo expandir los alcances a su conciencia, para que las personas puedan conducir una vida con más conocimiento de causa, libertad y posibilidad de elección.

Finalmente, todos sabemos que luchar contra la pobreza, es luchar para que la humanidad logre vivir en paz y armonía, y aquí, en un país tan pequeño, tan rico en cultura, pero tan pobre materialmente, haya una institución que desde un pequeño lugar, en medio de una sola cuadra, se esta trabajando por elevar y promover salud en las familias más necesitadas, y ojalá que con el tiempo puedan nacer más lugares y espacios de acogida, ya que creo es una forma también de acabar con este flagelo que tanto agobia a nuestra sociedad.

A la luz de estos tiempos, ahora puedo decir que entiendo más, la importancia de los lugares de acogida, y en especial, desde lo que se hace en la Casa de la Familia.

\section{REFERENCIAS BIBLIOGRÁFICAS}

1. Maza, B.(2001)La Casa de la Familia : Un lugar para acoger, escuchar y jugar. Lima: Trabajo para acceder a miembro titular de la Sociedad Peruana de Psicoanálisis.

2. Reflexiones en torno a la prevención temprana en salud mental y su relación con la pobreza. Lima: Casa de la Familia. (2001) Conversatorio La prevención temprana con niños y padres: Una nueva forma de lucha contra la pobreza.,.

3. Bettelheim, B. (2001). No hay padres perfectos. España: Editorial Critica.

4. Freud, S. (2003)Obras completas: Tomo II. Buenos Aires: Editorial El Ateneo.

5. Laplanche y Pontalis. (1996). Diccionario de psicoanálisis. Buenos Aires: Editorial Paidós.

6. Winnicott, D. W. (1980). El niño y el mundo externo. Buenos Aires: Editorial Horne. 